\title{
Rancang Bangun Automatic Liquid Filling Machine Berbasis IoT (Internet of Things)
}

\author{
Ahmad Syarif Rahmatullah ${ }^{1}$, Harianto ${ }^{2}$, Ira Puspasari ${ }^{3}$ \\ 1,2,3 Program Studi/Jurusan Teknik Komputer, Universitas Dinamika \\ Jl.Raya Kedung Baruk 98 Surabaya, 60298. \\ Email: 17410200013@dinamika.ac.id ${ }^{1}$,hari@dinamika.ac.id², ira@dinamika.ac.id ${ }^{3}$
}

\begin{abstract}
Abstrak: Perkembangan otomasi industri saat ini sangat berdampak pada efisiensi waktu dan biaya produksi. Hal ini juga didukung oleh berkembangnya sistem Internet of Things (IoT) pada Revolusi Industri 4.0. Sistem pengisi cairan pada botol ini, menerapkan IoT untuk monitoring proses produksi jarak jauh, tidak hanya itu kebutuhan akan keamanan data juga bisa terpenuhi. Penelitian ini mengaplikasikan mikrokontroler sebagai sistem utama pada mesin. Sensor dan aktuator untuk mengisi cairan kedalam botol. Pengujian yang dilakukan berupa monitoring dan keamanan data dengan 100\% tingkat keberhasilan pengisian cairan kedalam botol. Kecepatan melakukan pengisian kedua botol $100 \mathrm{ml}$ selama 6,8 detik. Rata-rata selisih dari kedua botol 1,3 ml. Rata-rata produksi per menit 10 botol. Waktu untuk sekali proses produksi selama 12 detik. Protokol MQTT digunakan untuk mengiriman data dengan persentase keberhasilan 100\%. Waktu rata-rata kecepatan pengiriman data 2 detik. Keamanan data dengan menggunakan aplikasi MQTT Panel memiliki persentase keberhasilan sebesar $100 \%$. Pengisi cairan kedalam botol secara otomatis dapat melakukan monitoring dengan kecepatan pengiriman data lebih cepat dibanding dengan kecepatan sistem produksi.
\end{abstract}

Kata Kunci: Internet of Things, MQTT, Filling Machine, Otomasi Industri

\begin{abstract}
Nowdays the development of industrial automation impacts the efficiency of time and production costs. It is also supported by the development of the Internet of Things (IoT) system which refers to the industrial revolution 4.0. One of the applications on an industrial scale is the liquid filling system on the bottle. The implementations of IoT allow monitoring of production processes, and data security. Microcontrollers as the main system in this research, sensors and actuators used to filled the liquid. This results of monitoring and data security $100 \%$ success rate of filling liquids. The time of filling both bottles is $100 \mathrm{ml}$ for 6.8 seconds. The average difference between the two bottles is $1.3 \mathrm{ml}$, the average production per minute are 10 bottles and 12 seconds each process. The MQTT protocol is $100 \%$ successfully used for data delivery protocols. The average time of data delivery speed is 2 seconds, data security 100\% successfully using the MQTT Panel application, and data delivery speed is 2 secon. Liquid fillers automation shows that the time of data delivery is faster than production system.
\end{abstract}

Keywords: Internet of Things, MQTT, Filling Machine, Automation Industries 
Ahmad Syarif Rahmatullah' dkk/ Journal of Technology Informatics (JoTI), Vol.2, No.2, April 2021, Hal $72-82$

\section{PENDAHULUAN}

Saat ini otomasi dengan menggunakan bantuan robot adalah sebuah pendekatan baru dalam proses bisnis. Hal ini dikarenakan user dapat dengan mudah mengerjakan hal yang berbeda dalam satu waktu, sistem otomasi ini juga menekan adanya kesalahan yang dibuat oleh pekerja [1]. Kunci utama sistem manufaktur saat ini adalah pengaruh dari teknologi eksponensial (manufaktur yang ditambah dengan autonomous robot, Internet of Things dan teknologi lain yang mengacu pada teknologi Industry 4.0 sebagai pemercepat atau katalis yang memmungkinkan solusi yang lebih fleksibel dan penghematan biaya pada proses industri [2].

Perkembangan ilmu pengetahuan dan teknologi dalam pengisian cairan ke dalam botol secara otomatis memerlukan sistem mekanik. Untuk dapat membuat sistem tersebut menjadi efisien dan berimbas baik pada dunia perindustrian. Dalam dunia industri, pengisian cairan dan proses penutupan botol menerapkan sistem otomasi yang menyebabkan proses produksi menjadi semakin singkat dan lebih akurat untuk keuntungan yang lebih tinggi pada perusahaan [3]. Sistem filling botol dalam industri kecil kurang efisien dikarenakan masih mnggunakan sistem secara manual [4]. Mesin otomatis pengisian air merupakan alat untuk digunakan sebagai mengisi produk atau bahanbahan untuk ke dalam botol. Bahan-bahan yang umum digunakan berupa cairan seperti : air mineral, susu, saus, madu, sirup, kecap dan lain sebagainya. Mesin otomatis pengisian air memiliki akurasi dengan tingkat yang presisi. Proses pengisian produk ke dalam botol menjadi efisien. Umumnya mesin otomatis pengisian air terkoneksi dengan PLC (Programmable Logic Controller) [5]

Beberapa penelitian sebelumnya MQTT pada lingkungan IoT (Internet of Things) merupakan solusi dengan sumber daya rendah. MQTT dapat digunakan untuk solusi dari sistem remote wireless. MQTT memiliki penundaan dari CoAP untuk packet loss yang rendah. Pesan pada MQTT berukuran kecil dan loss rate lebih kecil sama dengan $25 \%$, untuk memastikan transmisi handal CoAP menghasilkan extra traffic lebih kecil [6]. Untuk mempermudah dalam melakukan monitoring produk maka dibuatlah sistem IoT (Internet Of Things), dimana menggunakan protokol MQTT (Message Queue Telemetry Transport). Terdapat protokol yang sebelumnua digunakan untuk telemetry yaitu protokol MQTT.
Dimana sistem pada protokol tersebut connection oriented dan terpusat. Untuk protokol DSS merupakan protokol dengan sifat intelligent system dimana sistem tersebut connectionless dan tersebar. Pada Protokol MQTT terdapat 3 level QoS. Dimana terdapat level 0, 1, dan 2. [7]

IoT (Internet of Things) sebagai monitoring dan digunakan sebagai sarana untuk kemanan data rancang bangun tersebut. Dimana pada penelitian sebelumnya tentang rancang bangun ini belum ditambahkan sebuah sistem keamanan. Pada rancang bangun sebelumnya hanya melakukan sebuat monitoring pada liquid filling machine. Oleh sebab itu peneliti membuat rancang bangun rancang bangun automatic liquid filling machine berbasis IoT (Internet of Things) yang dapat melakukan monitoring dan juga menambahkan fitur keamanan pada rancang bangun tersebut. Makalah ini terbagi dari latar belakang penelitian, metode penelitian yang terdiri dari perancangan hardware dan software, hasil dan pembahasan serta kesimpulan dan saran.

\section{METODE PENELITIAN}

Penelitian ini merancang sebuah
automatic liquid filling machine yang
menggunakan digunakan input yang terdapat sensor untuk mendeteksi botol dan toggle switch yang digunakan untuk input mode standby dan running serta input mode online dan offline. Aktuator berupa solenoid pushpull untuk stopper input dan stooper out, pompa air untuk pengisian cairan ke dalam botol, synchronous motor untuk motor penggerak conveyor. Mikrokontroler sebagai pengendali sistem utama. Serta terdapat output berupa OLED untuk menampilkan data dan aplikasi MQTT Panel. Model perancangan dapat dilihat pada Gambar 1. Input yang digunakan pada penelitian ini adalah Sensor IR FC-51, yang berfungsi untuk mendeteksi botol dan menghitung jumlah botol. Toggle Switch berfungsi untuk mengatasi error gagal booting pada saat pertama kali mikrokontroler dinyalakan. Terdapat kondisi agar relay harus dalam keadaan mati sebelum dapat menyalakan mikrokontroler. Setelah mikrokontroler menyala maka toggle switch relay dapat dinyalakan untuk menghindari error gagal booting. Kemudian juga dapat digunakan untuk emergency apabila dibutuhkan. Toggle switch start digunakan untuk mengganti mode stanby dan mode run. Dimana pada mode stanby digunakan untuk kondisi dimana mesin bersiap untuk melakukan produksi 
Ahmad Syarif Rahmatullah' dkk/ Journal of Technology Informatics (JoTI), Vol.2, No.2, April 2021, Hal $72-82$

dan input password keamanan, mode run digunakan untuk mesin sedang dalam kondisi berjalan dan melakukan proses produksi. Toggle switch mode berfungsi sebagai switch untuk dapat memilih mesin dalam keadaan tersambung dengan internet atau tidak. Saat kondisi mode online maka mesin dapat terkoneksi dengan internet sedangkan pada kondisi mode offline mesin tidak akan terkoneksi dengan internet.

Mikrokontroler yang digunakan pada penelitian ini adalah Wemos D1 R2 yang dilengkapi dengan ESP8266 untuk dapat melakukan komunikasi data secara wireless. Mikrokontroler bertugas sebagai sistem yang melakukan otomatisasi dalam pengisian botol. Dimulai dari sensor yang mendeteksi botol pada conveyor dengan jumlah yang sesuai dengan nozzle sebanyak dua buah. Kemudian stopper in dan stopper out menyala digunakan untuk menghentikan botol agar sesuai dengan posisi nozzle. Proses pengisian cairan menggunakan pompa air yang diatur menggunakan delay timer sesuai dengan volume botol yang akan digunakan. proses berikutnya ketika pengisian selesai adalah stopper out akan mati. Setelah itu botol bisa kembali berjalan yang menandakan proses pengisian pada botol telah selesai dan mengulangi proses dari awal. Mikrokontroler juga digunakan untuk pengiriman data berupa monitoring dan kode password keamanan. Data yang dikirim kepada broker MQTT oleh mikrokontroler antara lain: data jumlah botol yang telah diproduksi akan diperoleh dari data deteksi pada sensor, data jumlah pengisian botol per menit, data durasi waktu penggunaan alat dalam satuan menit dan password untuk dapat memonitoring rancang bangun tersebut.

Beberapa aktuator yang digunakan untuk menjalankan proses pengisian botol secara otomatis sebagai berikut: Modul relay sebagai switch pada aktuator yang lain melalui kontak sinyal yang telah diberikan oleh mikrokontroler. Solenoid pushpull digunakan untuk stopper in untuk menghentikan botol yang masuk, stopper out untuk menghentikan botol yang keluar. Pompa air digunakan untuk proses pengisian cairan pada botol. Motor synchronous digunakan untuk menggerakkan belt pada conveyor agar botol bisa berjalan.

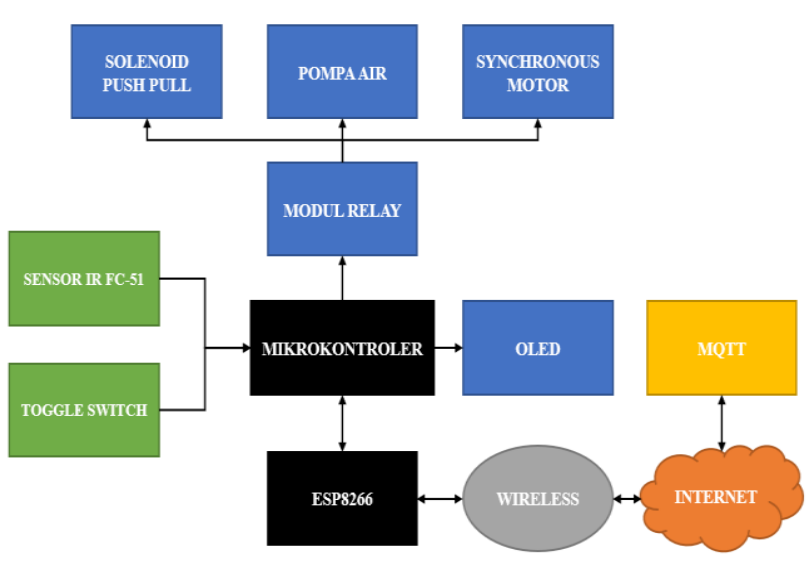

Gambar 1. Model Perancangan

Output pada rangkaian ini adalah pengisian cairan pada botol secara otomatis, sistem keamanan dimana hanya pengguna tertentu yang mengetahui password bisa melakukan monitoring menggunakan aplikasi MQTT Panel, dan informasi berupa monitoring keadaan sistem dan informasi tersebut dikirimkan melalui broker MQTT untuk monitoring pada aplikasi MQTT Panel. Saat mode offline dapat dilakukan monitoring pada OLED berupa tampilan data pengamatan produksi, produksi per menit, waktu sistem menyala dan keadaan sistem dalam keadaan menyala atau mati.

\section{Perancangan Perangkat Keras}

Perancangan Rangkaian Input digunakan untuk mendeteksi dan menghitung jumlah botol. Terdapattoggle switch yang diperlukan untuk fungsi $m$ ode online atau mode offline dan fungsi running atau stop rancang bangun tersebut. Datasheet rangkaian dapat dilihat pada Tabel 1. Perancangan aktuator terdapat pompa air yang digunakan untuk mengisi cairan pada botol. Terdapat solenoid push pull untuk fungsi stopper input dan stopper output. Synchronous motor digunakan untuk menggerakkan conveyor belt agar botol dapat berjalan sesuai yang diinginkan. Datasheet rangkaian aktuator dapat dilihat pada Tabel 2.

Rangkaian output terdapat OLED sebagai antar muka untuk menampilkan data yang perlu disampaikan kepada user. Datasheet rangkaian dapat dilihat pada Tabel 3 . 
Ahmad Syarif Rahmatullah dkk/ Journal of Technology Informatics (JoTI), Vol.2, No.2, April 2021, Hal 72-82

Perancangan sebuah conveyor yang digunakan untuk laju botol dapat dilihat pada Gambar 7.

Tabel 1. Datasheet Rangkaian Input

\begin{tabular}{cccc}
\hline Sensor & SwitchRun & SwitchMode & Wemos \\
\hline OUT & - & - & D5 \\
- & OUT & - & D6 \\
- & - & OUT & D7 \\
VCC & VCC & VCC & 5V \\
GND & GND & GND & GND \\
\hline
\end{tabular}

Tabel 2. Datasheet Rangkaian Aktuator

\begin{tabular}{ccccc}
\hline $\begin{array}{c}\text { Pompa } \\
\text { Air }\end{array}$ & $\begin{array}{c}\text { Stop } \\
\text { per in }\end{array}$ & $\begin{array}{c}\text { Stop } \\
\text { perout }\end{array}$ & $\begin{array}{c}\text { Con } \\
\text { veyor }\end{array}$ & $\begin{array}{c}\text { We } \\
\text { mos }\end{array}$ \\
\hline Relay1 & - & - & - & D0 \\
- & Relay2 & - & - & D3 \\
- & - & Relay3 & - & D4 \\
- & - & - & Relay4 & D8 \\
VCC & VCC & VCC & VCC & 5V \\
GND & GND & GND & GND & GND \\
\hline
\end{tabular}

Tabel 3. Datasheet Rangkaian Output

\begin{tabular}{cc}
\hline OLED I2C & WEMOS \\
\hline SCL & D1 \\
SDA & D2 \\
VCC & $5 \mathrm{~V}$ \\
GND & GND \\
\hline
\end{tabular}

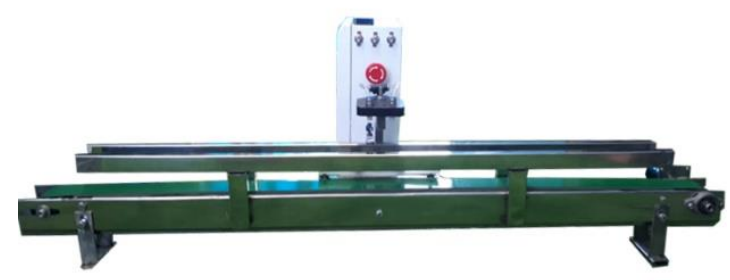

Gambar 2. Rancang Bangun pada Conveyor

Gambar 2. Menunjukkan rancang bangun conveyor pada penelitian ini, dimana botol yang berjalan secara otomatis melewati conveyor ini. Perancangan toggle switch, emergency button, OLED, dan holder solenoid pushpull untuk digunakan sebagai stopper input dan stopper output. Holder untuk nozzle yang digunakan untuk pengisian botol. Holder sensor untuk pendeteksi botol dapat ditunjukkan pada Gambar 3.

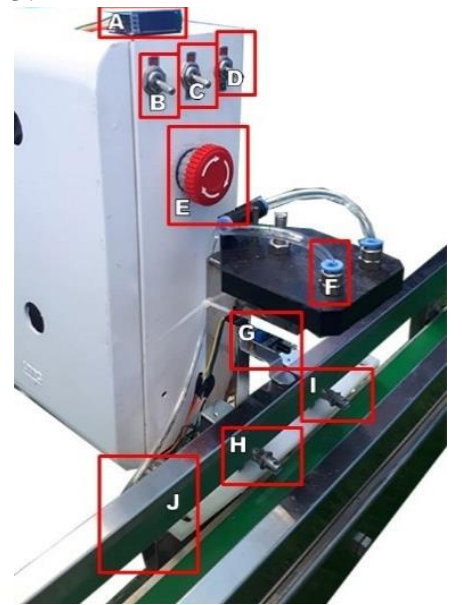

Gambar 3.Desain Penempatan Modul Pada Rancang Bangun

Keterangan pada Gambar 3:

1. $\mathrm{A}=$ OLED I2C

2. $\mathrm{B}=$ Toggle switch $12 \mathrm{~V}$

3. $\mathrm{C}=$ Toggle switch start

4. $\mathrm{D}=$ Toggle switch mode

5. $\mathrm{E}=$ Tombol emergency

6. $\mathrm{F}=$ Nozzle

7. $\mathrm{G}=$ Sensor IR FC-51

8. $\mathrm{H}=$ Stopper in

9. I = Stopper out

10. $\mathrm{J}=$ Pompa air

Rancangan panel listrik pada penelitian ini ditunjukkan pada Gambar 4.

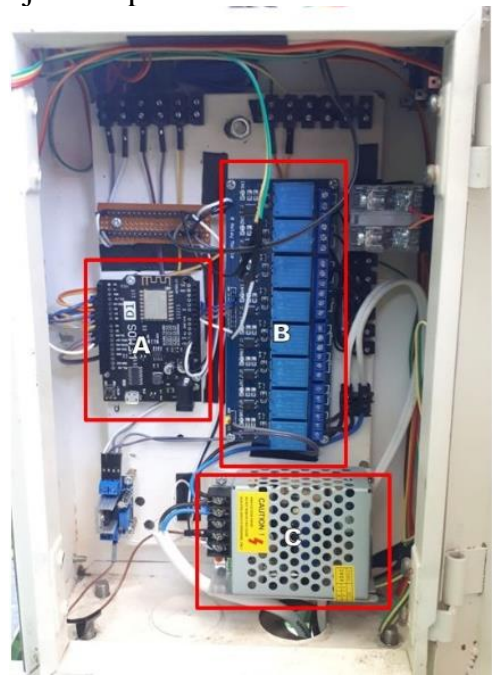

Gambar 4. Desain Penempatan Panel Listrik pada Rancang Bangun 
Ahmad Syarif Rahmatullah' dkk/ Journal of Technology Informatics (JoTI), Vol.2, No.2, April 2021, Hal 72-82

Keterangan pada Gambar 4:

1. $\mathrm{A}=$ Wemos D1 R2

2. $\mathrm{B}=$ Modul Relay

3. $\mathrm{C}=$ Power Supply

\section{Perancangan Perangkat Lunak}

dilanjutkan ke dalam mode inisialisasi. Mode inisialisasi digunakan untuk mengatasi pengisian pertama kali dimana pada saat pertama kali selang air dalam kondisi kosong yang menyebabkan volume dalam botol menjadi tidak terpenuhi.

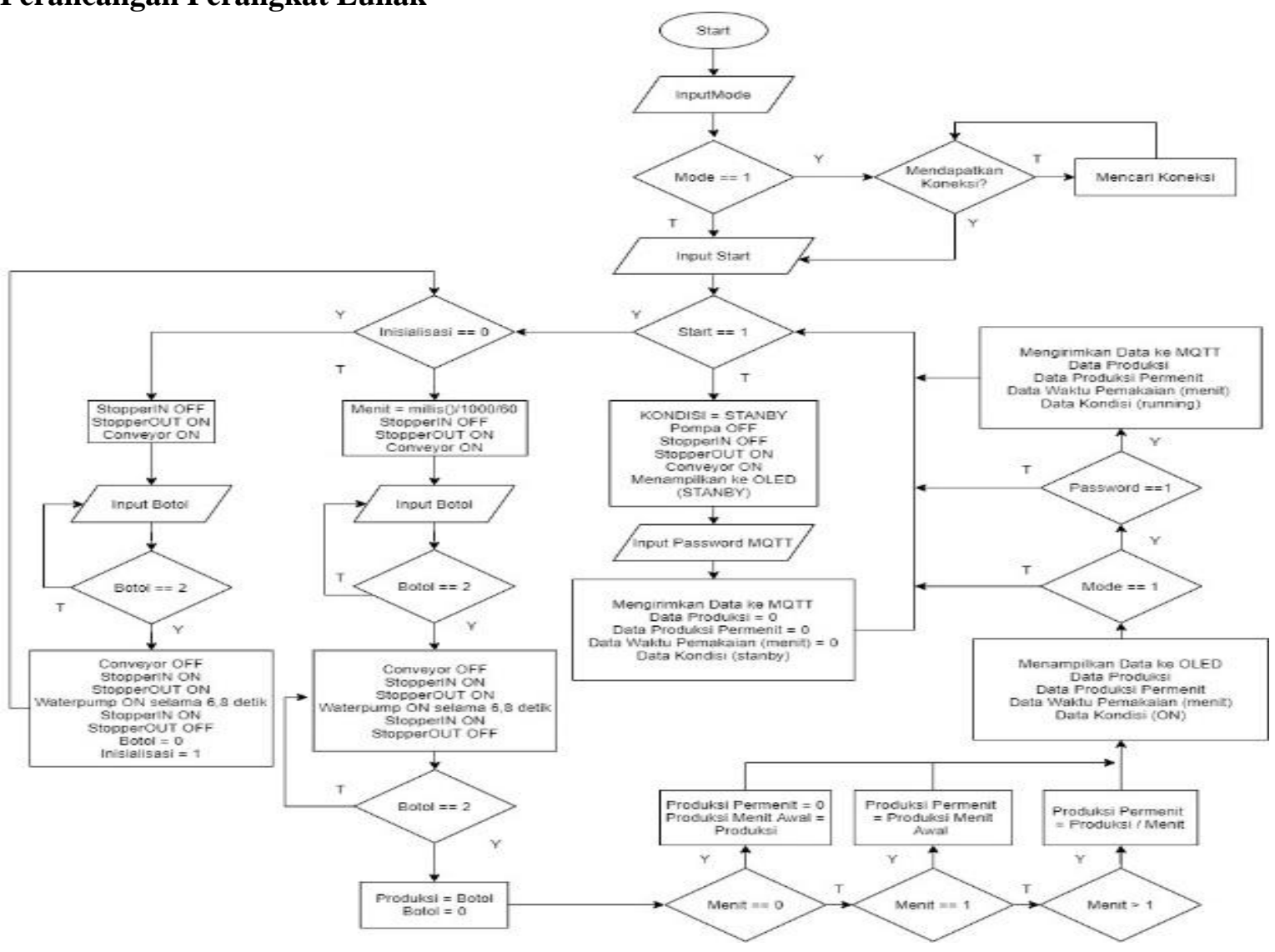

Gambar 5. Flowchat Program

Pada Gambar 5 menjelaskan bahwa sistem dimulai dari pemilihan mode dimana sistem tersebut memiliki dua buah mode online dan offline. Mode online dimulai dari pencarian koneksi pada perangkat untuk dapat terhubung dengan internet dan terhubung dengan MQTT. Saat menghubungkan sinyal pada wifi program akan terus berulang sampai mendapatkan alamat wifi berlaku sama dengan mengkoneksikan pada broker MQTT. Pada mode offline maka program langsung menuju pada pemilihan mode start atau mode stanby. Sedangkan mode stanby program menampilkan informasi pada layar OLED dan mengirimkan data pada broker MQTT dimana semua data dikirimkan menjadi 0 (nol) serta digunakan untuk input password. Setelah toggle switch start dalam keadaan menyala, kemudian
Kondisi inisialisasi hanya terjadi selama satu kali dan kemudian kembali pada mode start.

Sedangkan pada mode start program memulai dengan menyalakan conveyor dan dilanjutkan stopper input keadaan non aktif dan stopper output dalam keadaan aktif. Dilanjutkan dengan sensor yang mendeteksi bahwa terdapat dua botol. Setelah itu conveyor akan berhenti dan stopper input dan stopper output dalam keadaan non aktif.

Pompa air menyala untuk mengisi cairan ke dalam botol selama 6,8 detik. Proses selanjutnya conveyor menyala dan stopper output mati dan botol selesai diisi cairan. Botol yang telah terdeteksi sensor dicatat pada bagian produksi. Selanjutnya mencari perhitungan produksi per menit dimana data dalam produksi dibagi dengan data menit waktu rancang bangun 
Ahmad Syarif Rahmatullah' dkk/ Journal of Technology Informatics (JoTI), Vol.2, No.2, April 2021, Hal 72-82

di start. Data produksi, menit, produksi per menit, dan kondisi akan ditampilkan pada OLED. Saat mode online dilanjutkan dengan pengecekan password yang digunakan untuk keamanan untuk mengirimkan data produksi, menit, produksi per menit, dan kondisi yang akan dikirimkan ke broker MQTT. Sedangkan mode offline langsung menampilkan data pada OLED.

\section{HASIL DAN PEMBAHASAN \\ Pengujian Input}

Telah dilakukan pengujian pada sensor IR FC-51 dan toggle switch. Tabel 4 menunjukkan bahwa pengujian input sensor dan switch dengan persentase berhasil $100 \%$. Pengujian dilakukan saat sensor mendeteksi sebuah objek maka output yang dikeluarkan 0 (low), dan apabila sensor tidak mendeteksi sebuah objek maka output yang dikeluarkan 1 (high). Saat toggle switch dalam kondisi on maka output yang dikeluarkan 1 (high), sedangkan ketika dalam kondisi off maka output yang dikeluarkan 0 (low).

\section{Pengujian Aktuator}

Pengujian aktuator dapat berfungsi sesuai dengan program. Tabel 5 dan Tabel 6 merupakan hasil pengujian aktuator yang memiliki persentase keberhasilan 100\%. Aktuator yang diujikan berupa pompa air, stopperin, stopperout, dan conveyor. Pengujian pada aktuator berupa menyala dan mati sesuai dengan data yang telah ditampilkan pada serial monitor.

Tabel 4. Pengujian Input Sensor dan Switch

\begin{tabular}{|c|c|c|c|c|c|}
\hline No & $\begin{array}{l}\text { Sen } \\
\text { sor }\end{array}$ & $\begin{array}{l}\text { Swit } \\
\text { ch }\end{array}$ & $\begin{array}{l}\text { Serial } \\
\text { Moni } \\
\text { tor } \\
\text { Sensor }\end{array}$ & $\begin{array}{l}\text { Serial } \\
\text { Moni } \\
\text { tor } \\
\text { Switch }\end{array}$ & $\begin{array}{l}\mathrm{Ha} \\
\text { sil }\end{array}$ \\
\hline 1 & $\begin{array}{c}\text { Non } \\
\text { detect }\end{array}$ & ON & 1 & 1 & 1 \\
\hline 2 & $\begin{array}{l}\text { Non } \\
\text { detect }\end{array}$ & ON & 1 & 1 & 1 \\
\hline 3 & $\begin{array}{l}\text { Non } \\
\text { detect }\end{array}$ & ON & 1 & 1 & 1 \\
\hline 4 & $\begin{array}{l}\text { Non } \\
\text { detect }\end{array}$ & ON & 1 & 1 & 1 \\
\hline 5 & $\begin{array}{l}\text { Non } \\
\text { detect }\end{array}$ & ON & 1 & 1 & 1 \\
\hline \multicolumn{4}{|c|}{ Persentase Keberhasilan } & $100 \%$ & \\
\hline
\end{tabular}

Tabel 5. Pengujian Aktuator

\begin{tabular}{ccccc} 
No & $\begin{array}{c}\text { Pompa } \\
\text { Air }\end{array}$ & $\begin{array}{c}\text { Stopper } \\
\text { in }\end{array}$ & $\begin{array}{c}\text { Stopper } \\
\text { out }\end{array}$ & $\begin{array}{c}\text { Con } \\
\text { veyor }\end{array}$ \\
\hline 1 & Nyala & Nyala & Nyala & Nyala \\
2 & Nyala & Nyala & Nyala & Nyala \\
3 & Nyala & Nyala & Nyala & Nyala \\
4 & Nyala & Nyala & Nyala & Nyala \\
5 & Mati & Mati & Mati & Mati \\
\hline
\end{tabular}

Tabel 6. Pengujian Aktuator pada Serial Monitor

\begin{tabular}{cccccc}
\hline & Serial & Serial & Serial & Serial & \\
& Moni & Moni & Moni & Moni & Ha \\
No & tor & tor & tor & tor & Ha \\
& Pom & Stop & Stop & Con & sil \\
& pa & per & per & veyor & \\
& Air & in & out & Nyal & 1 \\
\hline 1 & Nyala & Nyala & Nyala & Nyala \\
2 & Nyala & Nyala & Nyala & Nyala & 1 \\
3 & Nyala & Nyala & Nyala & Nyala & 1 \\
4 & Nyala & Nyala & Nyala & Nyala & 1 \\
5 & Mati & Mati & Mati & Mati & 1 \\
\multicolumn{7}{c}{ Persentase Keberhasilan } & & $100 \%$ \\
\hline
\end{tabular}

\section{Pengujian Output}

Gambar 6 menunjukkan bahwa OLED dalam keadaan menampilkan informasi kepada user.

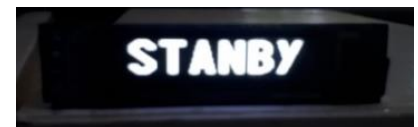

Gambar 6. OLED Dalam Keadaan Menampilkan Informasi

Pengujian OLED I2C berfungsi sesuai dengan program dan menampilkan informasi kepada pengguna sesuai dengan program.

\section{Pengujian Aplikasi MQTT Panel}

Gambar 7 merupakan konfigurasi aplikasi MQTT Panel untuk terhubung dengan broker. 
Ahmad Syarif Rahmatullah' dkk/ Journal of Technology Informatics (JoTI), Vol.2, No.2, April 2021, Hal 72-82

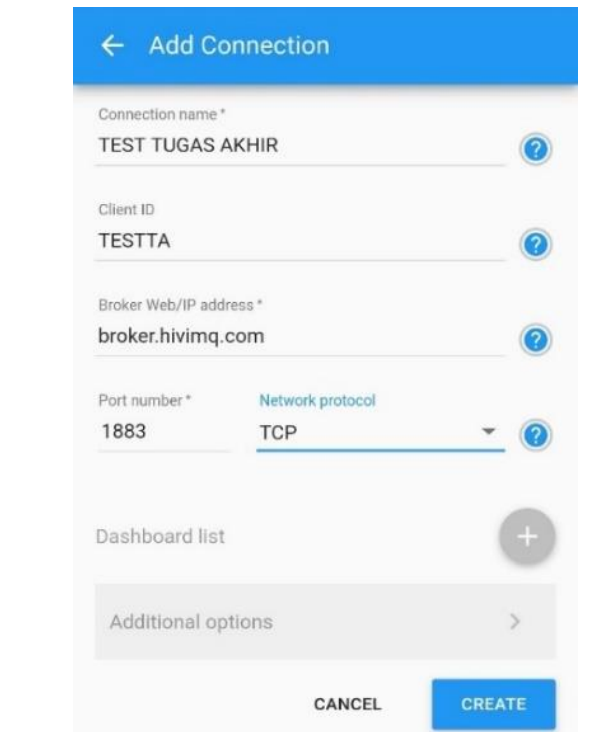

Gambar 7. Konfigurasi Koneksi MQTT Panel Dengan Wemos D1 R2

Gambar 8 merupakan konfigurasi aplikasi MQTT Panel untuk membuat panel yang berisi informasi data pada topik yang ditampilkan. Gambar 9 merupakan tampilan MQTT yang digunakan. Terdapat tampilan informasi grafik produksi, data produksi, data menit, data produksi per menit, data kondisi mesin dan password yang digunakan sebagai keamanan untuk pengiriman data. Gambar 10 menunjukkan contoh data yang dikirimkan oleh wemos kepada aplikasi MQTT panel. Kemudian data tersebut diterima oleh MQTT Panel dan ditampilkan pada aplikasi MQTT Panel. Telah dilakukan pengujian pengiriman data MQTT Panel dengan hasil data terkirim dan terdapat waktu kirim, seperti yang ditunjukkan pada Tabel 7.

Hasil pengujian waktu terima ditunjukkan pada Tabel 8 dengan hasil kecepatan kirim satu sampai dengan dua sekon. Terdapat hasil pengujian kecepatan kirim data produksi yang ditunjukkan pada Tabel 9. Sedangkan Tabel 10 menunjukkan penerimaan data per menit dengan kecepatan maksimal kirim selama dua sekon. Pengujian aplikasi MQTT Panel diperoleh kesimpulan bahwa wemos D1 R2 dapat berkomunikasi dengan aplikasi MQTT Panel sesuai dengan program. Pada Tabel 7, Tabel 8, Tabel 9 dan Tabel 10 telah dilakukan pengujian untuk kecepatan pengiriman data dari wemos ke broker MQTT. Dari pengujian pada Tabel 10 dapat diketahui bahwa rata-rata waktu kecepatan pengiriman data dengan 50 kali percobaan adalah
2 detik. Pengujian di atas menggunakan internet pribadi dengan kecepatan bandwidth sebesar $50 \mathrm{Mbps}$.

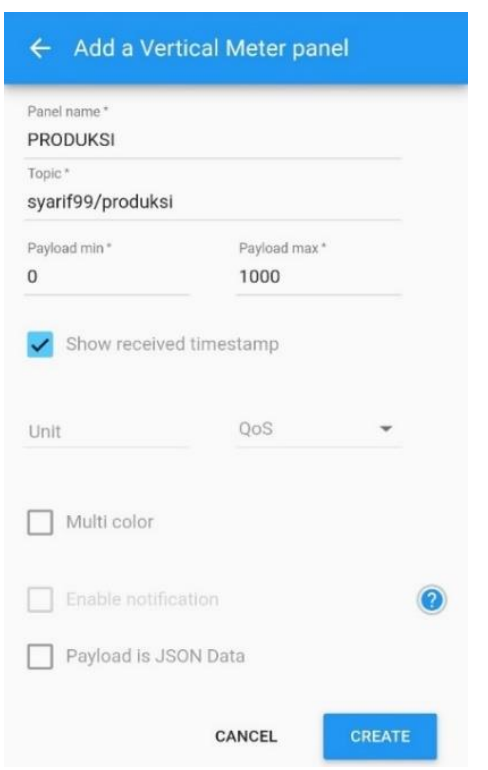

Gambar 8. Konfigurasi Panel Dalam Aplikasi

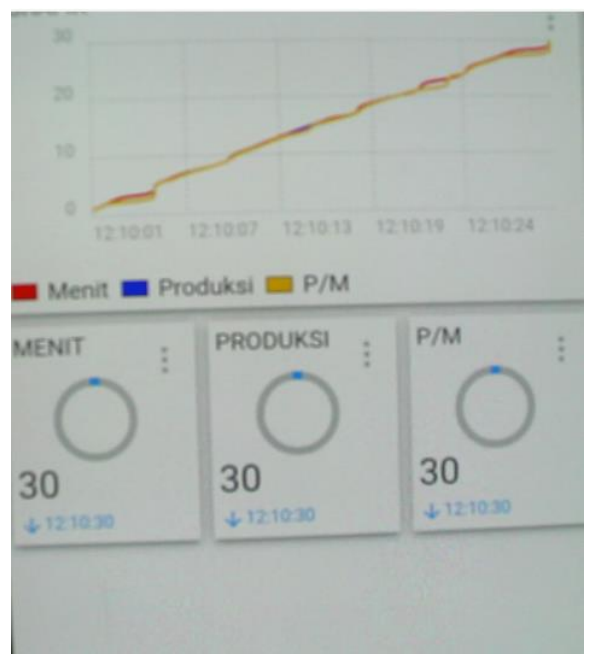

Gambar 9. Tampilan Aplikasi MQTT Panel yang Telah Terkoneksi 
Ahmad Syarif Rahmatullah' dkk/ Journal of Technology Informatics (JoTI), Vol.2, No.2, April 2021, Hal 72-82

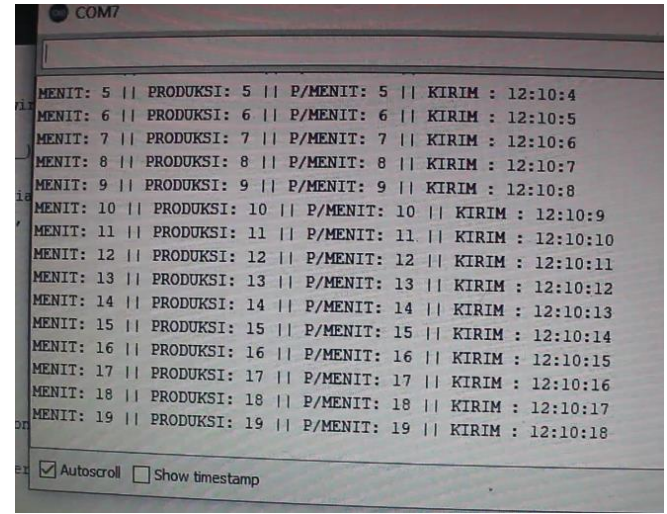

Gambar 10. Tampilan Serial Monitor Uji Coba Aplikasi MQTT Panel

Tabel 7. Pengujian Pengiriman Data MQTT Panel

\begin{tabular}{cccccc}
\hline No & $\begin{array}{c}\text { Data } \\
\text { Waktu }\end{array}$ & $\begin{array}{c}\text { Data } \\
\text { Pro } \\
\text { duksi }\end{array}$ & $\begin{array}{c}\text { Data } \\
\text { Per } \\
\text { menit }\end{array}$ & $\begin{array}{c}\text { Data } \\
\text { Kirim }\end{array}$ & $\begin{array}{c}\text { Waktu } \\
\text { Kirim }\end{array}$ \\
\hline 1 & 1 & 1 & 1 & Kirim & $12: 10: 00$ \\
2 & 2 & 2 & 2 & Kirim & $12: 10: 01$ \\
3 & 3 & 3 & 3 & Kirim & $12: 10: 02$ \\
4 & 4 & 4 & 4 & Kirim & $12: 10: 03$ \\
5 & 5 & 5 & 5 & Kirim & $12: 10: 04$ \\
\hline
\end{tabular}

Tabel 8. Pengujian Waktu Terima

\begin{tabular}{ccccc}
\hline No & $\begin{array}{c}\text { Data } \\
\text { Diterima }\end{array}$ & $\begin{array}{c}\text { Waktu } \\
\text { Terima }\end{array}$ & $\begin{array}{c}\text { Data } \\
\text { Wak } \\
\text { tu }\end{array}$ & $\begin{array}{c}\text { Kecepatan } \\
\text { Kirim (s) }\end{array}$ \\
\hline 1 & Diterima & $12: 10: 01$ & 1 & $00: 00: 01$ \\
2 & Diterima & $12: 10: 02$ & 2 & $00: 00: 01$ \\
3 & Diterima & $12: 10: 03$ & 3 & $00: 00: 02$ \\
4 & Diterima & $12: 10: 05$ & 4 & $00: 00: 02$ \\
5 & Diterima & $12: 10: 05$ & 5 & $00: 00: 01$ \\
\hline
\end{tabular}

Tabel 9. Pengujian Terima Data Produksi

\begin{tabular}{ccccc}
\hline No & $\begin{array}{c}\text { Data } \\
\text { Diteri } \\
\text { ma }\end{array}$ & $\begin{array}{c}\text { Waktu } \\
\text { Terima }\end{array}$ & $\begin{array}{c}\text { Data } \\
\text { Pro } \\
\text { duk } \\
\text { si }\end{array}$ & $\begin{array}{c}\text { Kece } \\
\text { patan } \\
\text { Kirim } \\
(\mathrm{s})\end{array}$ \\
\hline 1 & Diterima & $12: 10: 01$ & 1 & $00: 00: 01$ \\
2 & Diterima & $12: 10: 02$ & 2 & $00: 00: 01$ \\
3 & Diterima & $12: 10: 05$ & 3 & $00: 00: 02$ \\
4 & Diterima & $12: 10: 05$ & 4 & $00: 00: 02$ \\
5 & Diterima & $12: 10: 05$ & 5 & $00: 00: 01$ \\
\hline
\end{tabular}

Tabel 10. Pengujian Penerimaan Data Per menit

\begin{tabular}{ccccc}
\hline No & $\begin{array}{c}\text { Data } \\
\text { Diteri } \\
\text { ma }\end{array}$ & $\begin{array}{c}\text { Waktu } \\
\text { Terima }\end{array}$ & $\begin{array}{c}\text { Data } \\
\text { Per } \\
\text { menit }\end{array}$ & $\begin{array}{c}\text { Kece } \\
\text { patan } \\
\text { Kirim } \\
(\mathrm{s})\end{array}$ \\
\hline 1 & Diterima & $12: 10: 01$ & 1 & $00: 00: 01$ \\
2 & Diterima & $12: 10: 02$ & 2 & $00: 00: 01$ \\
3 & Diterima & $12: 10: 05$ & 3 & $00: 00: 02$ \\
4 & Diterima & $12: 10: 05$ & 4 & $00: 00: 02$ \\
. & & & & \\
. & & & & \\
. & & & & \\
50 & Diterima & $12: 10: 50$ & 50 & $00: 00: 01$ \\
\hline
\end{tabular}

\section{Pengujian Keseluruhan Sistem}

Gambar 11 menunjukkan proses pengisian cairan dalam botol. Dalam proses tersebut dimulai dengan stopper in dalam keadaan mati, stopper out dalam keadaan menyala dan conveyor menyala. Kemudian sensor mendeteksi bahwa ada dua buah botol yang terdeteksi, maka stopperin akan menyala, conveyor mati dan pompa air akan menyala selama 8 detik waktu yang dibutuhkan untuk mengisi botol sampai penuh. Setelah botol terisi maka pompa air akan mati dan stopperin menyala, stopperout mati serta conveyor juga akan menyala, dan kembali pada proses awal. Pada Gambar 12 merupakan contoh pengujian dimana pada mode stanby mengirimkan data 0 pada topik menit, produksi, dan produksi per menit. Serta akan mengirimkan data stanby pada aplikasi MQTT Panel. Pada mode stanby password bisa diinputkan baik itu password benar maupun password salah. Saat password yang diinputkan oleh MQTT Panel dalam keadaan benar, maka password akan terbuka yang digunakan untuk mengirim data monitoring pada saat produksi. Sebaliknya jika password yang diinputkan oleh MQTT Panel dalam keadaan salah, maka password akan terkunci dimana tidak akan mengirimkan data pada saat produksi. 


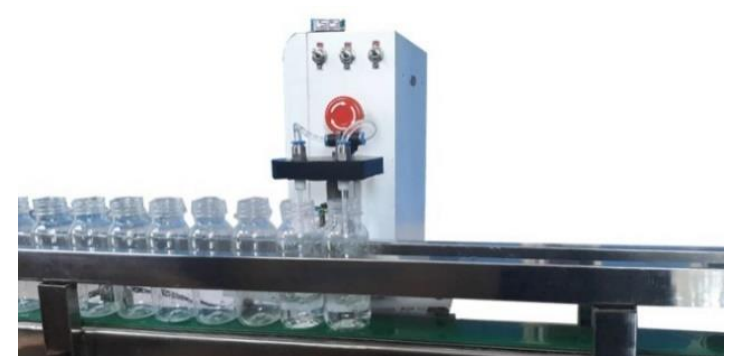

Gambar 2. Pengujian Pengisian Botol

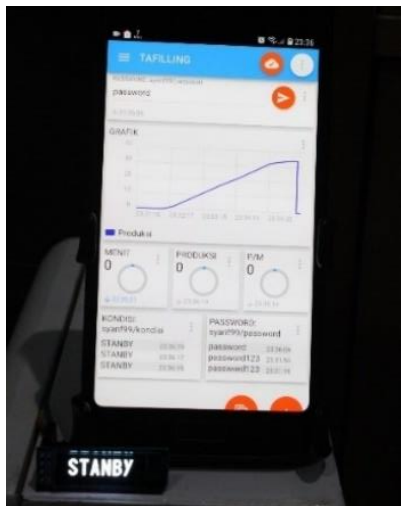

Gambar 3. Penujian MQTT pada Saat Stanby

Gambar 13 menunjukkan password dalam keadaan benar dan saat produksi berjalan maka akan mengirimkan data monitoring berupa topik menit, produksi, produksi per menit, dan kondisi. Saat password dalam keadaan salah dan pada saat produksi berjalan maka tidak akan mengirimkan data monitoring. Hal ini ditunjukkan pada Gambar 14. Tabel 11 merupakan hasil pengujian durasi waktu pompa air, diperoleh nilai bahwa untuk dapat mengisi botol dengan volume $100 \mathrm{ml}$ dibutuhkan waktu 6.8 detik. Tabel 12 merupakan hasil pengujian selisih volume filling nozzle diperoleh nilai rata-rata selisih volume antara nozzle 1 (satu) dan nozzle 2 (dua) sebesar $1,3 \mathrm{ml}$ dalam 30 kali percobaan.

Data pada Tabel 13 merupakan hasil pengujian Produksi Mesin Filling Dari 100 kali percobaan tersebut menghasilkan persentase keberhasilan sebesar $100 \%$ dan rata-rata produksi per menit berjumlah 10 botol. Data waktu di tabel tampak 0 menit, dikarenakan waktu awal berjalan produksi dihitung dari menit ke 0 , lalu berlangsung hingga 9 menit pada percobaan ke 100.

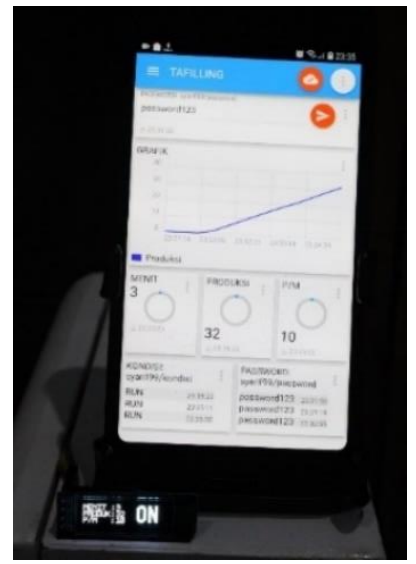

Gambar 13. Pengujian MQTT Password Benar

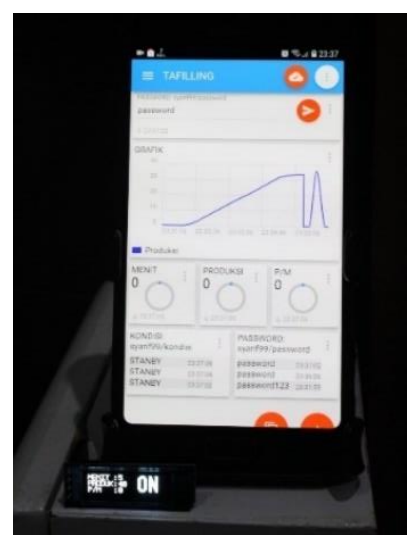

Gambar 14. Pengujian MQTT Password Salah

Tabel 11. Pengujian Durasi Waktu Pompa Air

\begin{tabular}{ccc}
\hline No & Durasi (s) & Volume (ml) \\
\hline 1 & 0,2 & 3 \\
2 & 0,4 & 6 \\
3 & 0,6 & 9 \\
4 & 0,8 & 12 \\
5 & 1 & 15 \\
\hline
\end{tabular}

Tabel 12. Pengujian Volume Filling Nozzle

\begin{tabular}{cccc}
\hline No & $\begin{array}{c}\text { Volume } \\
\text { Nozzle } 1 \\
(\mathrm{ml})\end{array}$ & $\begin{array}{c}\text { Volume } \\
\text { Nozzle } 2 \\
(\mathrm{ml})\end{array}$ & $\begin{array}{c}\text { Selisih } \\
(\mathrm{ml})\end{array}$ \\
\hline 1 & 100 & 98 & 2 \\
2 & 99 & 99 & 0 \\
3 & 100 & 98 & 2 \\
4 & 100 & 98 & 2 \\
5 & 99 & 99 & 0 \\
\hline
\end{tabular}


Ahmad Syarif Rahmatullah' dkk/ Journal of Technology Informatics (JoTI), Vol.2, No.2, April 2021, Hal 72-82

Tabel 13. Pengujian Produksi Mesin Filling

\begin{tabular}{ccccc}
\hline No & Produksi & Menit & $\begin{array}{c}\text { Produksi/ } \\
\text { Menit }\end{array}$ & $\begin{array}{c}\text { Ber } \\
\text { hasil }\end{array}$ \\
\hline 1 & 1 & 0 & 0 & 1 \\
2 & 2 & 0 & 0 & 1 \\
3 & 3 & 0 & 0 & 1 \\
4 & 4 & 0 & 0 & 1 \\
. & & & & \\
$\cdot$ & & & & \\
. & & & & \\
100 & 100 & 9 & 11 & 1 \\
\hline & Berikut & ini & Persamaan & untuk
\end{tabular}

menghitung kecepatan produksi:

$60 s /\left(\frac{\text { Rata-Rata Produksi Per menit }}{\text { Nozzle }}\right)$

Pengujian kecepatan produksi diperoleh dari rumus menghitung kecepatan produksi. Dimana pada pengujian produksi mesin filling diperoleh nilai rata-rata produksi per menit sebesar 10 botol. Kemudian dikarenakan terdapat 2 nozzle maka produksi per menit sebesar 10 botol akan dibagi dengan 2 nozzle yang menghasilkan nilai 5 produksi per menit jika menggunakan 1 nozzle. Kemudian untuk menghitung kecepatan produksi maka dilakukan pembagian dimana 60 detik dibagi dengan 5 produksi per menit. Dari perhitungan tersebut akan diperoleh nilai kecepatan produksi dari awal botol terdeteksi oleh sensor sampai selesai proses pengisian selama 12 detik. Tabel 14 menjelaskan pengujian keamanan dimana proses tersebut menghasilkan persentase keberhasilan sebesar $100 \%$. Pengujian komunikasi sistem menjelaskan proses seluruh pengujian sistem pada pengiriman berupa data menit, produksi, produksi per menit, dan kondisi. Pada penerimaan berupa data password. Proses percobaan tersebut menghasilkan persentase keberhasilan sebesar $100 \%$.

Hasil pengujian seluruh sistem dapat diamati bahwa pengujian berjalan sesuai dengan program. Pada pengujian mesin filling dibutuhkan bantuan operator untuk menjalankan mesin tersebut dan juga pengawasan ketika terjadi trouble pada mesin. Pada pengujian yang membutuhkan koneksi internet, pengujian tersebut dilakukan menggunakan koneksi internet pribadi dengan kecepatan bandwidth sebesar $50 \mathrm{Mbps}$.
Tabel 14. Pengujian Komunikasi Keamanan

\begin{tabular}{cccccc}
\hline No & $\begin{array}{c}\text { Data } \\
\text { Masuk }\end{array}$ & $\begin{array}{c}\text { Kon } \\
\text { disi }\end{array}$ & $\begin{array}{c}\text { MQTT } \\
\text { Pa } \\
\text { nel }\end{array}$ & $\begin{array}{c}\text { Data } \\
\text { me } \\
\text { mos }\end{array}$ & $\begin{array}{c}\text { Ber } \\
\text { hasil }\end{array}$ \\
\hline 1 & password & Terkunci & dikirim & $\begin{array}{c}\text { Diteri } \\
\text { ma }\end{array}$ & 1 \\
2 & $\begin{array}{c}\text { Password } \\
123\end{array}$ & Terbuka & dikirim & $\begin{array}{c}\text { Diteri } \\
\text { ma }\end{array}$ & 1 \\
3 & $\begin{array}{c}\text { Password } \\
123\end{array}$ & Terbuka & dikirim & $\begin{array}{c}\text { Diteri } \\
\text { ma }\end{array}$ & 1 \\
4 & $\begin{array}{c}\text { Password } \\
123\end{array}$ & Terbuka & dikirim & $\begin{array}{c}\text { Diteri } \\
\text { ma }\end{array}$ & 1 \\
5 & $\begin{array}{c}\text { Password } \\
12\end{array}$ & Terkunci & dikirim & $\begin{array}{c}\text { Diteri } \\
\text { ma }\end{array}$ & 1 \\
\hline
\end{tabular}

\section{KESIMPULAN}

Beberapa kesimpulan yang dihasilkan pada penelitian ini:

1. Pengisian cairan pada botol secara otomatis dapat berjalan dengan selisih Selisih pengisian kedua botol memiliki rata-rata 1,3 $\mathrm{ml}$. Memiliki kecepatan pengisian dua buah botol $100 \mathrm{ml}$ selama 6,8 detik. Keberhasilan sebesar $100 \%$ dan rata-rata produksi per menit sebanyak 10 botol serta kecepatan sistem pengisian botol selama 12 detik dalam 100 kali percobaan.

2. Rancang bangun dapat terkoneksi dengan internet dengan broker MQTT dalam pengiriman data dan penerimaan data yang digunakan pada jaringan IoT (Internet of Things) dengan persentase keberhasilan sebesar $100 \%$ dan kecepatan pengiriman data rata-rata selama 2 detik dalam 50 kali percobaan.

3. Rancangan bangun dapat menggunakan protokol MQTT dan dapat melakukan proses monitoring dan keamanan data dengan persentase keberhasilan sebesar $100 \%$, monitoring bisa dilakukan secara real time. Selisih dari kecepatan sistem produksi selama 12 detik dan kecepatan pengiriman data selama 2 detik.

\section{SARAN}

1. Menggunakan broker MQTT yang berbayar, yang berbayar memiliki tingkat keamanan lebih baik.

2. Mengganti jenis mikrokontrol berupa PLC untuk mendapatkan sistem yang stabil dan tahan dalam kondisi ekstrim. Serta memiliki 
Ahmad Syarif Rahmatullah dkk/ Journal of Technology Informatics (JoTI), Vol.2, No.2, April 2021, Hal $72-82$

banyak I/O untuk menunjang lebih banyak perangkat yang digunakan agar sistem lebih termekanisme dengan sempurna serta kecepatan produksi yang lebih tinggi.

3. Menggunakan mekanisme program yang dapat berjalan secara multitask yang digunakan untuk mengatasi stuck saat kehilangan koneksi internet ketika berjalan pada mode online.

\section{DAFTAR PUSTAKA}

[1] S. Yatskiv, I. Voytyuk and e. al, "Improved Method of Software Automation Testing Based on the Robotic Process Automation Technology," in International Conference on Advanced Computer Information Technologies (ACIT), Ceske Budejovice, Czech Republic, 2019.

[2] . V. M. P. F. D. E. D. F. R. Maicon Saturno, "Proposal Of An Automation Solutions Architecture For Industry 4.0," In 24th International Conference On Production Research, Lancaster, Pennsylvania 17602 U.S.A., 2017.

[3] S. Rumalutur And S. L. Allo, "Sistem Kontrol Otomatis Pengisian Cairan Dan Penutup Botol Menggunakan Arduino Uno Rev 1.3," Jurnal Electro Luceat, Pp. 23-34, 2019.

[4] F. G. Airlangga, A. Triwiyatno And Sumardi, "Perancangan Sistem Automasi Pada Pengemasan Susu Dalam Botol Dengan Programmable Logic Controller (Plc) Omron Cple Terhadap Purwarupa Filling Bottle And Capping Machine," Transient, Vol.6, No. 1, Pp. 103-109, 2017.

[5] P. C. Hermawan, D. Notosudjono And Waryani, "Perancangan Miniatur Mesin Pengisian Air Otomatis Menggunakan Arduino Nano Berbasis Internet Of Things (Iot)," Program Studi Teknik Elektro, Fakultas Teknik-Universitas Pakuan, 2020.

[6] G. Y. Saputra, A. D. Afrizal, F. K. R. Mahfud, F. A. Pribadi And F. J. Pamungkas, "Penerapan Protokol Mqtt Pada Teknologi Wan (Studi Kasus Sistem Parkir Univeristas Brawijaya)," Jurnal Informatika Mulawarman, 2017.

[7] S. O. F. Tarigan, H. I. Sitepu and M. Hutagalung, "Pengukuran Kinerja Sistem Publish/ Subscribe Menggunakan Protokol MQTT (Message Queuing Telemetry
Transport)," Jurnal Telematika, vol. 9 no. 1 , pp. 25-30, 2014. 